\title{
ALIMENTOS FUNCIONAIS E NUTRACÊUTICOS: UMA PROPOSTA DE EDUCAÇÃO NUTRICIONAL A PARTIR DO ENSINO DE BIOQUÍMICA
}

\author{
REBELLO, Thiago José Jesus ${ }^{1}$ \\ FERNANDES, André Fillipe de Freitas ${ }^{1}$ \\ FOLINO, Carolina Habergric ${ }^{1}$ \\ DUARTE, Taíze Jesus ${ }^{1}$ \\ FONTES, Reynaldo Guedes de Oliveira ${ }^{1}$ \\ NASCIMENTO, Juliene Ribeiro ${ }^{1}$ \\ ESPERANÇA, Thamyres Cristina Rosa Boa ${ }^{1}$ \\ LAGE, Débora de Aguiar ${ }^{2}$
}

\begin{abstract}
RESUMO
O presente trabalho teve como objetivo colocar o discente em papel de protagonismo na produção do saber, da experimentação à divulgação, consolidando a educação nutricional a partir do ensino de bioquímica. A pesquisa teve um caráter qualitativo e foi estabelecida em três etapas: aula dialógica sobre alimentos funcionais e nutracêuticos; aula prática de identificação de compostos orgânicos; pesquisa e produção de folhetos informativos para divulgação científica. Durante as atividades, observamos que muitos alunos desconheciam as propriedades nutricionais básicas dos alimentos indispensáveis em uma dieta saudável e funcional. A aula prática no laboratório provocou grande motivação nos alunos, favorecendo o potencial investigativo, estimulando a observação e o raciocínio. A pesquisa e a produção textual culminaram na produção de folhetos de qualidade, os quais foram divulgados com sucesso. Por fim, concluímos que este estudo contribuiu para ampliar a base de conhecimentos teóricos sobre Educação Nutricional e seus resultados apontam para a importância da contextualização dos conteúdos curriculares na busca de uma aprendizagem significativa.
\end{abstract}

Palavras-chave: Nutrição e saúde - Alimentos funcionais e nutracêuticos - Ensino de bioquímica - Contextualização curricular.

\footnotetext{
${ }^{1}$ Estudante de Graduação em Ciências Biológicas da Universidade do Estado do Rio de Janeiro (IBRAG/UERJ) e Bolsista PIBID do subprojeto de Biologia do CAp-UERJ.

2 Professora Assistente do Instituto de Aplicação Fernando Rodrigues da Silveira (CAp-UERJ) e Coordenadora do subprojeto PIBID de Biologia do CAp-UERJ. Email: deboraalage@yahoo.com.br
} 


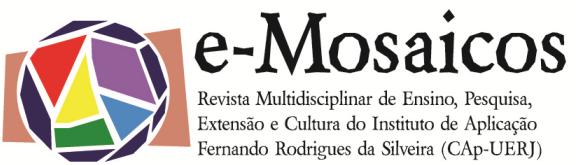

\begin{abstract}
This study aimed to put the students in a leading role in the production of knowledge, from experimentation to disclosure, consolidating nutrition education from biochemistry teaching. The research qualitative in character and was conducted in three steps: dialogic lecture on functional foods and nutraceuticals; class practice to identify organic compounds; research and production of information flyers for science communication. During the activities, we observed that many students did not know the basic nutritional properties of food necessary for a healthy and functional diet. The practical class in the laboratory motivated the students, favoring their potential for investigation and stimulating observation and reasoning. Research and text production culminated in producing quality flyers, which were successfully released. Finally, we conclude that this study helped to broaden the base of theoretical knowledge of Nutrition Education and its results show the importance of contextualization of curriculum content in the search for meaningful learning.
\end{abstract}

KEYWORDS: Nutrition and health - Functional foods and nutraceuticals - Teaching biochemistry Curriculum context.

\section{INTRODUÇÃO}

\subsection{Alimentação e SAÚde nA eSCOLA}

No panorama mundial, a industrialização, os avanços tecnológicos e a consolidação da mulher no mercado de trabalho são alguns fatores que, ao longo do tempo, influenciaram no aumento do consumo de alimentos altamente calóricos e de baixo valor nutricional por muitas crianças e adolescentes (MULLER et al., 2001; WANG et al., 2002; WORLD HEALTH ORGANIZATION, 2003). Como consequência à adoção destas práticas, nas últimas décadas têm se observado o aumento da prevalência de sobrepeso e da obesidade infantil, condições associadas a doenças crônicas, como hipertensão, arteriosclerose e diversos tipos de câncer, refletindo negativamente na qualidade de vida destes jovens (SOUZA et al., 2004).

Em contrapartida, neste mesmo período, também foi possível verificar um crescimento expressivo nas pesquisas sobre alimentos que poderiam auxiliar na prevenção ou no tratamento de doenças, os chamados alimentos funcionais. Estes podem apresentar diferentes conceitos dependendo da regulamentação adotada pelo país, sendo definido no Brasil como "todo aquele alimento ou ingrediente que, além das funções nutricionais básicas, quando consumido na dieta usual, produz efeitos metabólicos e/ou fisiológicos benéficos à saúde, devendo ser seguro para o consumo, sem supervisão médica", segundo a portaria nº 398 de 30/04/99, da Secretaria de Vigilância Sanitária do Ministério da Saúde (PIMENTEL et al., 2005).

Neste cenário, especialistas da indústria alimentícia passaram a concentrar seus esforços na busca de estratégias nutritivas modernas, voltadas para consumidores que acreditam na saúde a partir de uma alimentação correta ou via suplementação alimentar. Deste modo, muitos suplementos divulgados pela mídia audiovisual e digital são caracterizados como nutracêuticos, termo criado no final da década de 80 , a partir da combinação das palavras nutrição e farmacêutico. De acordo com Kumar e colaboradores (2012), os nutracêuticos são metabólitos obtidos a partir de diferentes organis- 


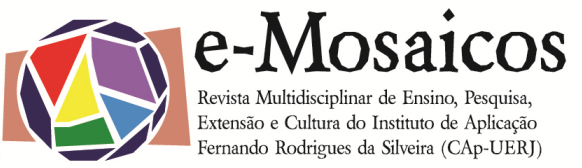

mos, que possuem propriedades medicinais comprovadas e que, ao serem adicionados ao alimento convencional, passam a adquirir um valor nutritivo.

Neste contexto, diante da necessidade de modificar o quadro nutricional apresentado pela maioria dos jovens, torna-se fundamental o desenvolvimento de práticas educativas que visem estimular uma dieta mais adequada em busca de melhor qualidade de vida. Sendo assim, a escola apresenta-se como um espaço privilegiado para a construção e a consolidação de práticas alimentares saudáveis, no qual as atividades voltadas à Educação em Saúde podem apresentar grande repercussão. Adicionalmente, neste ambiente estão inseridas todas as dimensões do aprendizado: ensino, relações lar-escola-comunidade, além de ambiente físico e emocional, fatores que podem beneficiar os estudantes em etapas fundamentais de suas vidas.

Acreditamos que a existência de um ambiente promotor de vivências que valorizem práticas saudáveis, constitui-se propícia para a implantação de um programa bem sucedido de Educação ou, como discute Boog (1999), de "uma proposta pedagógica de ensino baseada na situação concreta de vida". Assim, diversos centros de pesquisas internacionais como a American Dietetic Association (ADA), a Society for Nutrition Education e a American School Food Service Association (ASFSA), têm destacado a importância das instituições de ensino na formação de hábitos saudáveis, por meio de diversas intervenções que englobam programas de educação nutricional (BRIGGS et al., 2003). Deste modo, é natural a expectativa mundial de que a escola funcione como ambiente para promoção de Saúde e Educação Nutricional.

Neste caso, entende-se que a implantação de programas de educação nutri- cional nas escolas e a consequente criação de um ambiente favorável à alimentação voltada para a saúde, constituam estratégias importantes para combater a obesidade infantil e as doenças crônicas a ela associadas (JAIME e LOCK, 2009; JULIANO et al., 2009). Lembrando a frase de Paulo Freire, do livro Pedagogia da Autonomia, "de nada adianta o discurso competente se a ação pedagógica é impermeável a mudanças", e este é um desafio que nos impõe a pensar e refletir. Desafios em avançar nas práticas cotidianas desenvolvidas no campo da educação alimentar e nutricional.

\subsection{A Bioquímica na educação básica}

Assumindo a relevância da escola na promoção da saúde, as disciplinas de Ciências e Biologia adquirem papel de destaque, especialmente nos saberes referentes ao ensino de Bioquímica (PIRES, 2011). Esta área aplicada da ciência "aborda (...) a Biologia e a Química, que se complementam para explicar muitos fenômenos que ocorrem nos sistemas vivos" (GOMES e MESSEDER, 2013, p.2). Adicionalmente, relaciona-se com diversos assuntos em voga nos últimos anos, como câncer, Alzheimer, diabetes (MOREIRA, 2007), sendo essencial para a compreensão da diversidade de nutrientes que consumimos - ou deveríamos consumir - em nossa alimentação (PIRES, 2011).

Contudo, diversos estudos apontam a pouca apreensão dos conceitos de Bioquímica pelos estudantes da educação básica, que geralmente apresentam grande dificuldade para interpretar tabelas nutricionais (PIRES, 2011). Neste caso, a valorização da memorização de conceitos e rotas metabólicas (GOMES e MESSEDER, 2013), o alto grau de abstração do conteúdo (BARBOSA et al., 2012) e a pouca aplicabilidade na 


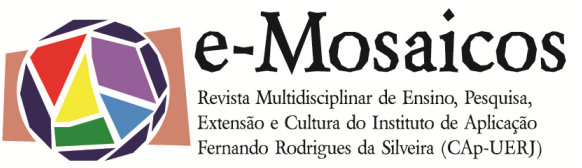

forma como é tratado (MOREIRA, 2007), podem ser a causa para essa dificuldade na aprendizagem. Gomes e Messeder (2013) relatam ainda que, na maioria dos casos, os professores apenas abordam o início e o fim dos fenômenos bioquímicos, como forma de simplificar o tema, sem perceber que tal estratégia acaba prejudicando o entendimento global do processo.

Diante deste quadro, é necessário que o professor fortaleça seu arcabouço teórico e desenvolva um olhar analítico, capaz de conduzir a transição do paradigma narrativo-contemplativo para o dialógicoparticipativo (GOMES e MESSEDER, 2013). O construtivismo surge, então, como forma de atingir essa transição, ao passo que se apropria dos conhecimentos prévios do aluno para construir novos conceitos, levando à recomposição das estruturas cognitivas (BARBOSA et al., 2012). Dias e colaboradores (2013, p.26) comentam:

"A teoria do aprendizado significativo de Ausubel sugere que o aluno apenas aprende aquilo que tem um significado para ele, e isso só é possível se os novos conceitos são formados a partir de conhecimentos previamente adquiridos (AUSUBEL et al., 1980). A metodologia construtivista de ensino sugere que o professor seja apenas um mediador, pois assim os alunos têm um papel ativo no processo de ensino-aprendizagem. Ou seja, essa metodologia leva em conta a bagagem de conhecimento adquirida anteriormente, que deve ser valorizada pelo professor e pela escola."

Deste modo, a utilização de recursos didáticos que se apropriem do conhecimento do aluno e o transportem da posição passiva para a postura ativa no processo de ensino-aprendizagem, pode contribuir significativamente para a incorporação dos conteúdos (VIEIRA et al., 2011). Para Barbosa e colaboradores (2012), a inclusão de analogias à exposição do professor constitui uma forma simples de reunir o saber prévio, o domínio análogo, aos novos conceitos, o domínio alvo.

Neste caso, além da discussão em sala de aula, a experimentação desponta como estratégia essencial ao ensino de Bioquímica, facilitando a compreensão dos processos (DIAS et al., 2013). Segundo Gomes e Messeder (2013), quando o processo de ensino-aprendizagem é dialógico, este consegue fazer do aluno um agente ativo, tornando viável a apropriação do conteúdo e a problematização frente a temas cotidianos com os quais ele esteja interligado. De qualquer modo, entendendo o processo de aprendizagem como complexo, recomendase que o professor lance mão de uma combinação de diferentes técnicas e recursos, de modo a atender à diversidade de preferências de aprendizagem (DIAS et al., 2013).

O presente trabalho tem como objetivo colocar o discente em papel de protagonismo na produção do saber, da experimentação à divulgação, consolidando a educação alimentar, a partir do estudo dos alimentos funcionais e nutracêuticos, durante o ensino de bioquímica.

\section{METODOLOGIA}

O campo de ação deste estudo foi o Colégio Estadual João Alfredo, localizado no bairro de Vila Isabel, Rio de Janeiro. O trabalho foi desenvolvido com cinco turmas do segundo ano do Ensino Médio, totalizando cerca de duzentos estudantes. A metodologia descrita nesta pesquisa apresenta um caráter qualitativo, no qual os pesquisadores buscam realizar uma abordagem voltada para o comportamento, a interpretação, as experiências vividas e a relação com 0 am- 


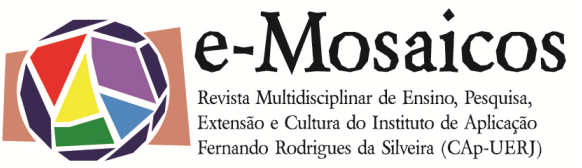

biente das pessoas que estão sendo estudadas (DOS ANJOS, 2007).

$\mathrm{Na}$ busca pela construção de conhecimentos científicos sobre alimentos funcionais e nutracêuticos e seus benefícios à saúde humana, este trabalho foi estabelecido em três etapas: aula expositiva dialógica, aula prática experimental, pesquisa e produção de folhetos informativos.

\section{Aula expositiva dialógica}

Para iniciar a temática com estudantes, foi realizada uma aula expositiva dialógica, na qual um notebook e um projetor multimídia foram utilizados como recursos didáticos. Segundo diversos autores (NASCIMENTO, 2009; ALVES et al., 2013), a aula expositiva dialógica ou dialética, caracteriza-se por valorizar os saberes dos alunos na construção do conhecimento científico. Deste modo, o professor tem o papel de estimular e direcionar discussões em sala de aula, mediando a produção de novos saberes.

No material didático apresentado aos alunos foram enfatizados: os principais conceitos acerca de alimentos funcionais e nutracêuticos; os principais nutrientes funcionais e sua possível identificação a partir das cores dos alimentos; e a estreita relação entre a qualidade da alimentação consumida e o desenvolvimento de doenças no organismo. A aula expositiva durou cerca de $\mathbf{5 0}$ minutos.

\section{Aula prática experimental}

Após a discussão teórica, os estudantes participaram de uma aula prática experimental, a qual teve por objetivo a identificação dos principais nutrientes orgânicos presentes nos alimentos. A atividade prática foi conduzida no laboratório de Ciências da escola, a partir da realização de quatro experimentos simples: teste para identificação de carboidratos, teste para lipídios, teste para proteínas e extração de DNA (ácido desoxirribonucléico). Antes do início das práticas, cada aluno recebeu um roteiro contendo um resumo sobre o assunto abordado (compostos orgânicos), a descrição metodológica de todos os experimentos a serem realizados, bem como algumas questões a serem respondidas (Anexo).

Ao final de cada experimento, os resultados observados e as conclusões obtidas eram discutidas coletivamente, a fim de auxiliar os estudantes no preenchimento do roteiro. Toda a atividade prática no laboratório teve duração de 50 minutos.

\section{Pesquisa e produção de folhetos informati- vos}

Na última etapa do trabalho, os alunos foram estimulados a desenvolver uma pesquisa sobre alimentos funcionais e nutracêuticos sugeridos no tratamento e na prevenção de doenças relacionadas aos aparelhos digestório, cardiovascular e urinário. Para tal, a divisão dos grupos utilizada na aula prática foi mantida e cada grupo sorteou uma determinada doença, que seria objeto do seu estudo.

A pesquisa foi realizada no laboratório de informática da escola, onde os estudantes foram orientados a buscar referências específicas para auxiliar na pesquisa, bem como a elaborar um folheto informativo em formato digital, produzido com o uso do software Microsoft Power Point disponível nos computadores da escola. Como meta final da pesquisa, cada grupo deveria produzir um folheto informativo sobre a sua temática específica sorteada. Ao final do trabalho, todos os folhetos produzidos fo- 
ram reunidos e expostos em formato de banner na feira de ciências da escola.

\section{Resultados e Discussão}

\subsection{Aula dialógiCa e ATIVIDADe PRÁtICA SOBRE ALIMENTOS FUNCIONAIS E NUTRACÊUTICOS}

No primeiro contato, foi observado que uma grande parcela dos educandos desconhecia as propriedades nutricionais básicas que uma dieta adequada deve proporcionar para o bom funcionamento do organismo. Deste modo, durante a aula dialógica sobre a importância do consumo regular de alimentos funcionais, verificou-se que os discentes eram capazes de elencar facilmente os principais nutrientes essenciais ao organismo, porém não obtiveram sucesso no momento de apontar algumas refeições nas quais esses nutrientes estivessem presentes.

A realização de uma aula prática experimental no laboratório foi recebida com grande entusiasmo pelos estudantes, os quais se mostravam bastante motivados para a atividade (Figura 1). No primeiro experimento do teste para carboidratos, 0 corante lugol foi utilizado para a identificação do polissacarídeo amido presente na farinha de trigo. Este corante apresenta na sua composição $2 \%$ de iodeto de potássio e $1 \%$ de iodo, o qual reage com a molécula de amido, resultando em uma estrutura que pode apresentar cores que variam desde 0 azul até o preto.

Neste caso, ao aplicar algumas gotas de lugol sobre a farinha de trigo foi possível identificar a presença do amido a partir da coloração azul resultante da reação. Além disso, o uso da farinha de trigo na atividade tornou clara a relação entre o conhecido aporte energético de pratos contendo mas- sas, batata ou outros tubérculos, e a presença desse carboidrato (NELSON e COX, 2002).

Os lipídeos são biomoléculas que incluem os óleos, as ceras e as gorduras, os quais apresentam função energética no organismo. Tais moléculas possuem características hidrofóbicas devido à presença de longas cadeias de hidrocarbonetos, sendo insolúveis em água. Esta insolubilidade foi verificada pelos alunos durante o segundo experimento ao adicionar óleo vegetal em um recipiente com água. Esta etapa da atividade foi fundamental, pois a insolubilidade em água atuou como um importante parâmetro para destacar a composição lipídica de óleos e gorduras, contextualizando o diálogo sobre as diversas doenças cardiovasculares relacionadas à má alimentação (CERVATTO, 1997).

No terceiro experimento, a adição do sulfato de cobre foi essencial para a identificação de proteínas presentes no leite, uma vez que este reagente, em pH alcalino proporcionado pela adição de hidróxido de sódio, interage com os átomos de nitrogênio dos aminoácidos, formando um complexo de coloração cada vez mais próxima do violeta, de acordo com o teor de proteína presente no alimento. Assim, a partir deste experimento foi possível estabelecer uma intensa discussão sobre a função estrutural das proteínas (NELSON e COX, 2002), notadamente presentes no leite materno (MARQUES et al., 2004) e nos suplementos para atletas (ROCHA e PEREIRA, 1998).

O conjunto de atividades sobre os compostos orgânicos foi finalizado com a prática de extração caseira de DNA, utilizando o morango. Os ácidos nucleicos presentes em todos os organismos constituem polímeros formados por nucleotídeos, e incluem o DNA e o RNA (ácido ribonucléico), moléculas responsáveis pela hereditariedade 
e pela expressão das informações genéticas, respectivamente. Adicionalmente, o DNA, encontrado no interior do núcleo das células eucarióticas, diferencia-se do RNA pelo tipo de glicídio, pela presença da base nitrogenada timina e por ser uma molécula formada por uma dupla fita de nucleotídeos, as quais se mantêm unidas por ligações do tipo pontes de hidrogênio.

Durante o experimento, a adição de detergente visando ao rompimento das membranas fosfolipídicas das células de morango, possibilitou a discussão de conceitos sobre a estrutura e as propriedades da membrana plasmática, bem como a localização do DNA no interior das células. De forma similar, a necessidade de maceração dos morangos favoreceu o diálogo sobre a importância da parede celular vegetal, a qual apresenta função de sustentação e de proteção contra choques osmóticos e impactos mecânicos (RAVEN et al., 2007). Neste sentido, ao final da prática, os estudantes puderam comprovar a presença de DNA nos alimentos, o que antes era refutado pela maioria.

Segundo diversos autores, a realização de atividades práticas possibilita a observação de fenômenos, a formulação de hipóteses, a experimentação e a reflexão dos resultados, favorecendo o desenvolvimento da capacidade investigativa, sendo fundamentais na construção do conhecimento científico dos estudantes (GOLDBACH et al., 2009; PITANGA et al., 2010; JUNQUEIRA, 2012). Sendo assim, a aula prática foi de suma importância para o elo entre as esferas do saber informal e o saber escolar, proporcionando, de forma enriquecedora, um grande envolvimento dos alunos e contribuindo significativamente na elaboração de novos conhecimentos.

\subsection{Produção de folhetos informativos}

No último momento deste trabalho, os estudantes produziram folhetos informativos, a partir de uma pesquisa sobre os principais alimentos e nutrientes capazes de prevenir e/ou tratar uma determinada doença. A partir da orientação dos educadores, os estudantes, divididos em grupos, produziram diversos folhetos em formato digital, abordando diferentes problemas relacionados à fisiologia humana. Deste modo, verificamos que 0 encontro entre a motivação dos alunos e o auxílio dos educadores, favoreceu a produção de trabalhos muito interessantes. Os folhetos abordaram diversos problemas frequentes na população, como: mau hálito, intestino preso, gastrite e úlcera, cálculo biliar, colesterol elevado, anemia ferropriva, cálculo renal, cirrose hepática, hipertensão e varizes (Figura 2). 

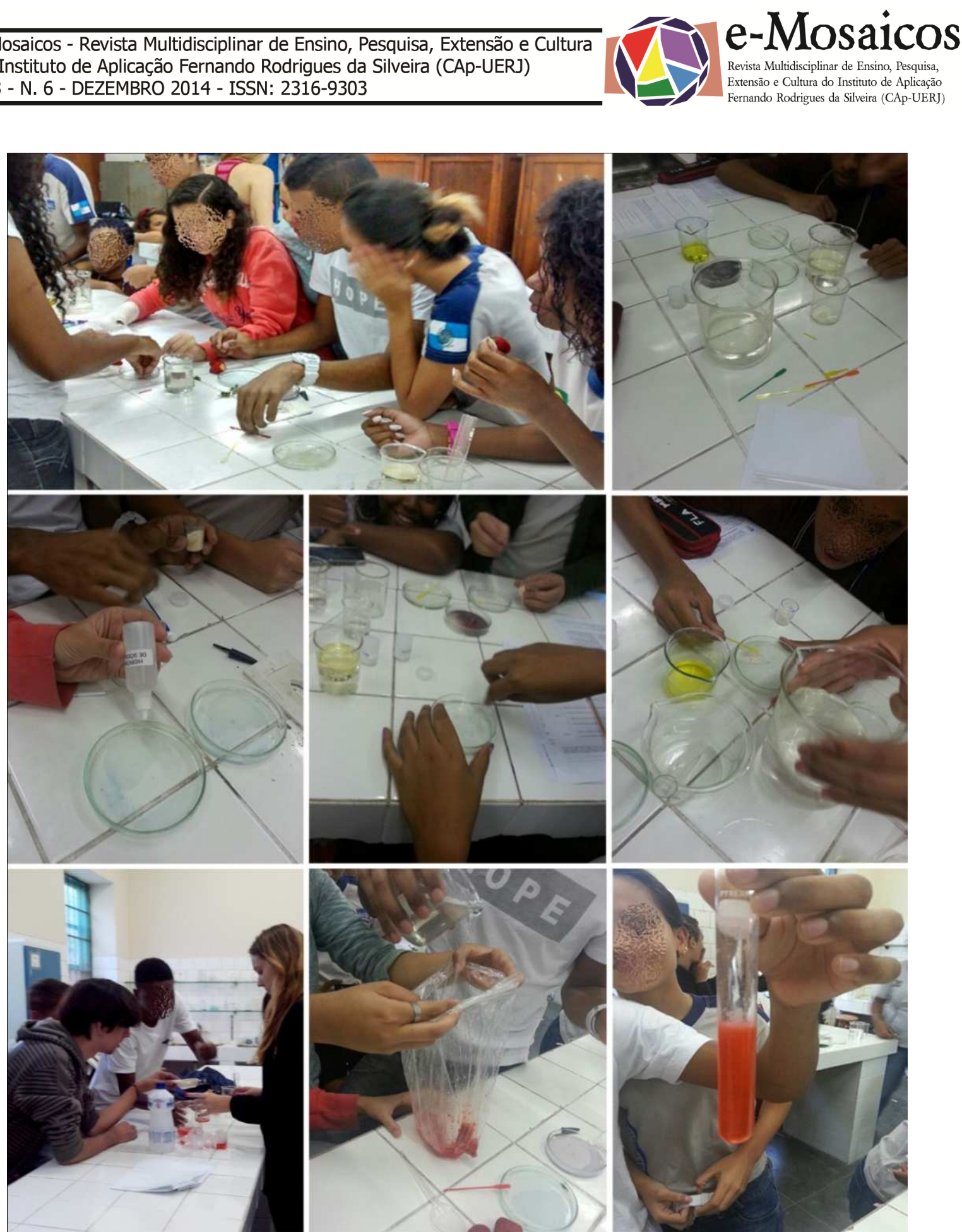

Figura 1: Aula prática experimental de identificação de nutrientes orgânicos realizada no laboratório de Ciências da escola. 


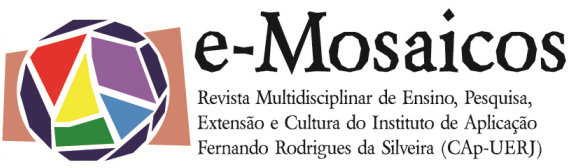

Em um estudo realizado a partir de oficinas relacionadas à alimentação e à nutrição, Solymos (2006) destacou a importância da escola como promotora da saúde, interpretando como sendo de sua responsabilidade integrar a saúde e a educação, entendendo que esta última implica em conscientização, ou seja, criação de indivíduos autônomos, críticos e capazes de problematizar situações e tomar decisões. Adicionalmente, Mateus e Gonçalves (2012) apontam para a importância da divulgação científica no âmbito escolar, visando não apenas socializar as informações científicas e tecnológicas produzidas na academia, mas também discutir de que forma podemos empregá-las na melhoria da qualidade de vida.

Neste sentido, a pesquisa e a confecção dos folhetos informativos, além de representarem um exercício de produção textual na disciplina de Biologia, também contribuíram com benefícios sociais, através da divulgação à comunidade escolar durante a feira de ciências. Segundo Vieira e colaboradores (2001), a produção de conhecimento científico na área da bioquímica dos alimentos cresce de modo contundente desde 1970, porém, a maior parte da produção fica restrita ao ensino superior (GOMES e MESSEDER, 2013).

Assim, a escola tem papel fundamental na promoção da divulgação científica, uma vez que grande parcela da população não tem acesso ou não compreende a importância das informações divulgadas. Para Tiago (2010), a divulgação científica atua como uma eficiente ferramenta na democratização da informação para a sociedade, enquanto Silva (2011, p.723) ressalta que "o conhecimento e o acesso ao conhecimento devem ser tratados como fatores estratégicos para um projeto de desenvol- vimento, sobretudo de perspectiva emancipatória". Deste modo, no cotidiano escolar, cabe ao professor a busca por novas estratégias que visem aproximar o estudante do saber científico, auxiliando-o na construção de conhecimentos, habilidades e valores necessários à tomada de decisões sobre questões de ciência e tecnologia.

\section{Considerações finais}

As atividades desenvolvidas no Colégio estadual João Alfredo tiveram como principal objetivo fazer do estudante o ator principal de todas as ações, estimulando constantemente o seu envolvimento e interesse. Assim, um modelo educacional que visa formar cidadãos conscientes e críticos, não deve ser pautado apenas na apreensão de conceitos científicos, mas especialmente na construção de atitudes desejáveis, de valores socialmente orientados e na capacidade de reflexão. Assim, acreditamos que a possibilidade de investigar, trocar, experimentar, comparar, ler, discutir e organizar, sob a mediação do professor, pode facultar ao aluno esses desenvolvimentos.

As práticas alimentares são resultados de decisões, conscientes ou não, estreitamente relacionadas à cultura alimentar da região, à tradição alimentar do convívio social e às transformações decorridas do acesso à informação científica e popular. No entanto, no campo do conhecimento da alimentação e da nutrição, mais do que proporcionar o acesso às informações, é fundamental estimular a autonomia dos indivíduos, para que estes possam atuar intencionalmente e com liberdade, fato que, sem dúvidas, demanda um consistente processo educativo. 
e-Mosaicos - Revista Multidisciplinar de Ensino, Pesquisa, Extensão e Cultura do Instituto de Aplicação Fernando Rodrigues da Silveira (CAp-UERJ)

V. 3 - N. 6 - DEZEMBRO 2014 - ISSN: 2316-9303
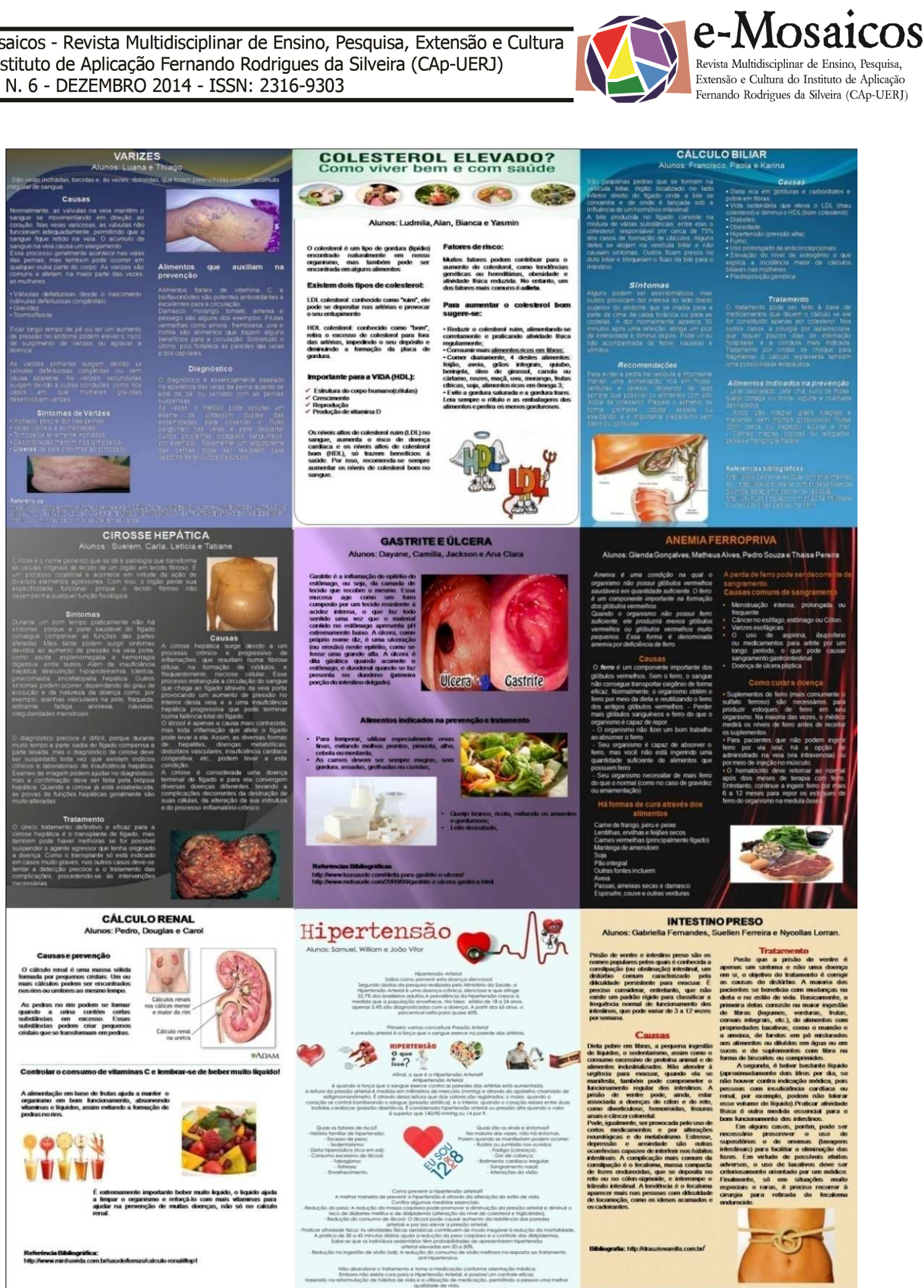

Figura 2: Folhetos informativos produzidos pelos estudantes acerca dos alimentos funcionais e nutracêuticos utilizados na prevenção e no tratamento de doenças. 


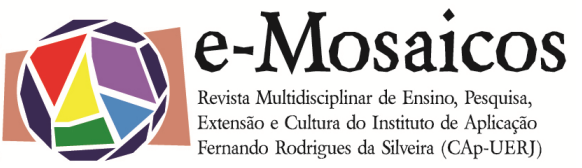

É nesse propósito que a educação alimentar e nutricional, na perspectiva desta atividade, desempenha uma função estratégica para a promoção de hábitos alimentares saudáveis. Na linha de Restrepo Mesa (2005), considera-se a educação alimentar e nutricional como um dispositivo de ações coordenadas, sendo mais que um instrumento, que requer o envolvimento de diferentes setores e disciplinas, a exemplo das ciências biológicas e das ciências sociais e humanas. Adicionalmente, o aprofundamento das discussões em torno das dimensões teórico-epistemológicas na interface da saúde-educação-nutrição, abordando temas como os alicerces científicos das práticas pedagógicas culturais que balizam a relação dos sujeitos e suas práticas alimentares são exemplos de questões emergentes a tratar.

Por fim, no contexto apresentado, consideramos que este trabalho contribuiu para ampliar a base de conhecimentos teóricos sobre Educação Nutricional, sugerindo a necessidade de prosseguimento dos estudos e destacando a importância da contextualização dos conteúdos curriculares na busca de uma aprendizagem significativa.

\section{REFERÊNCIAS BIBLIOGRÁFICAS:}

ALVES, C. R. R.; CAMPOS, J. C.; MOREIRA, J. B. N.; NOBRE, T. S.; SANCHES, I. C.; FORJAZ, C. L. M.; BRUM, P. C. Fisiologia do Exercício para alunos de graduação: uso de estratégias de ensino baseadas na metodologia dialética. Revista Brasileira de Educação Física e Esporte, v. 27, n. 2, p. 289-296, 2013.

AUSUBEL, D. P.; NOVAK, J. D.; HANESIAN, $\mathrm{H}$. Psicologia Educacional. Rio de Janeiro: Interamericana, 1980.
BARBOSA, J. U.; LEAL, M. C.; ROSSI, S. Q.; DIAS, T. N.; FERREIRA, K. A.; OLIVEIRA. C. $P$. Analogias para o ensino de Bioquímica no nível médio. Revista Ensaio, v. 14, n. 1, p. 195-208, 2012.

BOOG, M. C. F. Educação nutricional em serviços públicos de saúde. Cadernos de Saúde Pública, 15(s.2), S139-S147, 1999.

BRIGGS, M.; SAFAII, S.; BEALL, D. L.; American Dietetic Association; Society For Nutrition, Education; American School Food Service Association. Position of the American Dietetic Association, Society for Nutrition Education, and American School Food Service Association - Nutrition services: an essential component of comprehensive school health programs. Journal of the American Dietetic Association, v. 103, n. 4, p. 505-514, 2003.

BUSS, P. M. Promoção e educação em saúde no âmbito da Escola de Governo em Saúde da Escola Nacional de Saúde Pública. Caderno de saúde pública, v. 15, p. 177185, 1999. Suplemento.

CERVATO, A. M. Dieta habitual e fatores de risco para doenças cardiovasculares. Revista de Saúde Pública, v.31, n.3, p.227-35, 1997.

DIAS, G.; OLIVEIRA. F. S.; PASCUTTI, P. G.; BIANCONI, M. L. Desenvolvimento de ferramentas multimidiáticas para o ensino de bioquímica. Revista Práxis, ano V, n. 9, 2013.

DOS ANJOS, G. Pesquisa Qualitativa em estudos sobre Terceiro Setor: uma análise nos artigos apresentados no Semead. In: IV SEGeT - Simpósio de Excelência em Gestão e Tecnologia. Resende, 2007. 


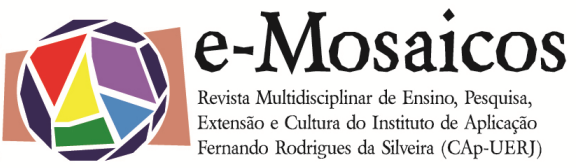

FREIRE, P. Pedagogia da autonomia: saberes necessários à prática educativa. 25. ed. São Paulo: Paz e Terra. 1996. $146 \mathrm{p}$.

GOLDBACH, T.; PAPOULA, N. R. P.; SARDINHA, R. C.; DYSARZ, F. P.; CAPILÉ B. Atividades práticas em livros didáticos de biologia: investigações e reflexões. Revista Perspectivas da Ciência e Tecnologia, v.1, n.1, 2009.

GOMES, L. M. de J. B. e MESSEDER, J. C. A presença das TIC no ensino de Bioquímica: uma investigação para uma análise crítica da realidade. Atas do IX Encontro Nacional de Pesquisa em Educação em Ciências - IX ENPEC, Águas de Lindóia, SP, 2013.

JAIME, P.C. e LOCK, K. Do school based food and nutrition policies improve diet and reduce obesity? Preventive Medicine, v. 48, p. 45-53, 2009.

JULIANO, B.; CERVATO-MANCUSO, A. M.; GAMBARDELLA, A. M. D. Educação nutricional em escolas de ensino fundamental do município de Guarulhos, SP. Mundo

saúde, v. 33, n. 3, p. 264-272, 2009.

JUNQUEIRA, N. E. G. ENSINO DE FISIOLOGIA VEGETAL: elaboração de material didático com enfoque prático direcionado a alunos e professores do ensino médio. Dissertação (Mestrado) Pontifícia Universidade Católica de Minas Gerais. Programa de Pós-Graduação em Ensino de Ciências e Matemática, 2012.

KUMAR, S.; KANT, S.; PARASHAR, B. Nutraceuticals as important critical supplements. Novel Science International Journal of Pharmaceutical Science, v. 1, n. 8, p. 574-579, 2012.
MARQUES, R. F. S. V.; LÓPEZ, F. A.; BRAGA, J. A. P. O crescimento de crianças amamentadas com leite materno exclusivo nos primeiros 6 meses de vida. Jornal de Pediatria, v. 80, n. 2, p. 99-105, 2004.

MATEUS, W. D. e GONÇALVES, C. B. Divulgação científica: o discurso e as possibilidades na internet. Anais do $2^{\circ}$ Simpósio em Educação em Ciências na Amazônia e VII Seminário de Ensino de Ciências na Amazônia, Manaus, AM, 2012. Disponível em:

$<$ https://www.academia.edu/3785095/DIVU LGA\%C3\%87\%C3\%830_CIENT\%C3\%8DFI CA_O_DISCURSO_E_AS_POSSIBILIDADES NA_INTERNET > Acesso em agosto de $201 \overline{3}$.

MESA, R. S. L. La promoción de la salud y sus aportes a La educación em alimentación y nutrición. Investigación y Educación en Enfermería, v. 23, n. 1, p. 110-117, 2005.

MOREIRA, L. M. O uso do corpo como ferramenta pedagógica: um modelo alternativo que desconsidera a ausência de recursos específicos para o ensino de bioquímica e biologia molecular no ensino fundamental. Revista Brasileira de Ensino de Bioquímica e Biologia Molecular, n. 1, 2007.

MULLER, M. J.; MAST, M.; ASBECK, I.; LANGNASE, K.; GRUND, A. Preventions of obesity - it is possible? Obesity Reviews, v. 2, n. 1, p. 15-28, 2001.

NASCIMENTO, J. M. 0 papel das interações sociais e atividades no processo de ensino-aprendizagem em aulas de química. Dissertação (Mestrado em Ensino de Ciências) - Departamento de Educação, Universidade Federal Rural de Pernambuco, Recife, 2009. $124 \mathrm{f}$. 


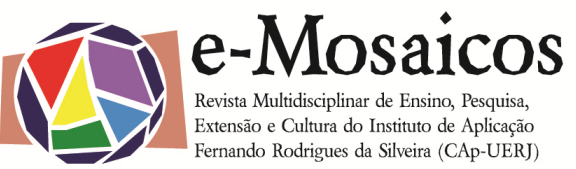

NELSON, D. L.; COX, M. M. Lehninger: princípios de bioquímica. 3. ed. São Paulo: Sarvier, 2002. 975p.

PIMENTEL, B. M. V.; FRANCKI, M.; GOLLÜCKE, B. P. Alimentos funcionais: introdução as principais substâncias bioativas em alimentos. São Paulo: Editora Varella, 2005.

PIRES, N. L. Bioquímica no Ensino Médio: Importância das Noções de Nutrição e Hábitos Alimentares. Trabalho de Conclusão de Curso do Curso de Licenciatura em Ciências Biológicas da Universidade de Brasília, Brasília, 2011. 37 f.

PITANGA, A. F.; SANTOS, L. D.; MELO, W. A. L. A fotossíntese como tema de atividade investigativa para o ensino de ciências em turmas de $3^{\circ}$ ano do ensino fundamental. In: XV Encontro Nacional de Ensino de Química. Brasília, 2010. Disponível em: <http://www.xveneq2010.unb.br/editorial.h $\mathrm{tm}>$. Acesso em fevereiro de 2011.

RAVEN, P. H.; EVERT, R. F.; EICHHORN, S. E. Biologia Vegetal. 5. ed. Rio de Janeiro: Guanabara Koogan, 2007. 728 p.

ROCHA, L. P. da; PEREIRA, M. V. L. Consumo de suplementos nutricionais por praticantes de exercícios físicos em academias. Revista de Nutrição, v. 11, n. 1, 1998.

SILVA, A. M.; LAZZAROTTI FILHO, A.; SILVA, A. P. S. Divulgação e apropriação do conhecimento científico: o caso da Educação Física. Liinc em Revista, v. 7, n. 2, p. 720732, 2011.

SOLYMOS, G. A centralidade da pessoa na intervenção em nutrição e saúde. Estudos avançados, v. 20, n. 58, p. 111-122, 2006.
SOUZA, M. R.; BEZERRA, C. S.; MAZZARIOL, R. A.; LEITE, B. P. F.; LIBERATORE, R. D. P. Análise da prevalência de resistência insulínica e diabetes mellitus tipo 2 em crianças e adolescentes obesos. Arquivos de Ciências da Saúde, v. 11 , n. 4, p. 215-218, 2004.

TIAGO, S. S. Divulgação científica e educação. In: Divulgação científica e educação, Salto para o futuro/TV Escola (MEC), Brasília, p.5-8, 2010. Disponível em: $<$ http://tvbrasil.org.br/ saltoparaofuturo/boletins.asp>. Acesso em janeiro de 2014.

VIEIRA, L. Q.; NICOLI, J. R.; PRADO, V. F.; SANTORO, M. M.; TEIXEIRA, S. M. R. Abordagem Prática Para o Ensino de Bioquímica. Revista Brasileira de Ensino de Bioquímica e Biologia Molecular, v. 1, 2011.

WANG, Y.; MONTEIRO, C.; POPKIN, B. $M$. Trends of obesity and underweight in older children and adolescents in the United States, Brazil, China, and Russia. The American Journal of Clinical Nutrition, v. 75, p. 971-977, 2002.

WORLD HEALTH ORGANIZATION. WHO Global strategy on diet, physical activity and health. Consultation process. 2003. Disponível em: <http://www.who.int/hpr/ qs.consultation.document.shtml>. Acesso em maio de 2014. 


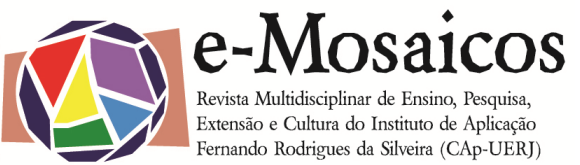

\section{ANEXO - Roteiro da atividade prática sobre nutrientes orgânicos}

\section{IDENTIFICANDO COMPOSTOS ORGÂNICOS}

O que comemos ou deixamos de comer está muito associado à saúde e ao estilo de vida de cada um. $\mathrm{O}$ adulto que pratica exercícios físicos com certa regularidade, o idoso com problemas cardíacos e o jovem em fase de crescimento têm necessidades diferentes. Sendo assim, é importante conhecer bem o que comemos. Será que o seu almoço tem carboidrato suficiente para te dar energia para o resto do dia? Ou será que o seu lanche tem gordura demais pra sua dieta? Nos experimentos abaixo, aprenderemos a identificar alguns dos principais compostos orgânicos presentes nos alimentos.

\section{EXPERIMENTO 1: TESTE PARA IDENTIFICAÇÃO DE CARBOIDRATOS}

Os carboidratos, ou açúcares, constituem a principal fonte de energia das células. Eles estão presentes no pão, no mel, no macarrão, na batata, entre outros. Um exemplo desses compostos é o amido, um polissacarídeo conhecido como "açúcar das plantas", por ser a forma na qual esses seres vivos armazenam carboidratos. No experimento a seguir, verificaremos quem possui amido na sua composição: a farinha de trigo, a batata ou o açúcar comum.

$$
\begin{array}{c|l}
\text { Etapa I } & \begin{array}{l}
\text { - Dissolva na placa um pouco de farinha de trigo / batata em água. } \\
\text { - Com que cor ficou a solução? }
\end{array} \\
\text { Etapa II } & \begin{array}{l}
\text { - Repita o processo utilizando açúcar de cozinha ao invés de farinha. } \\
\text { - Com que cor ficou a solução? }
\end{array}
\end{array}
$$

O lugol é um corante composto principalmente por iodo que forma um complexo roxo ao interagir com moléculas de amido. Desta forma, como podemos explicar a diferença entre a coloração das etapas I e II?

\section{EXPERIMENTO 2: TESTE PARA IDENTIFICAÇÃO DE LIPÍDIOS}

Os lipídios incluem os óleos, as ceras e as gorduras. Eles desempenham função de reserva energética, além de atuar como isolante termoelétrico e amortecedor mecânico. Neste experimento vamos observar que os lipídios apresentam características muito diferentes dos outros compostos, como viscosidade e polaridade.

\footnotetext{
- Adicione um pouco de óleo na placa de Petri.

\begin{tabular}{l|l} 
Etapa I & - Em outra placa, adicione um pouco de água com açúcar. \\
& - Repouse a ponta de uma folha de papel toalha em cada placa.
\end{tabular}

- Observe como cada líquido é absorvido pelo papel.
}
- Complete a outra metade com óleo.
- Observe como os dois líquidos interagem.


Considerando a etapa I, que diferença é observada no comportamento entre o óleo e a água com açúcar? Qual explicação química para esta diferença?

Considerando a etapa II, como podemos explicar a forma como óleo e água com açúcar interagiram ao serem misturadas no béquer?

\section{EXPERIMENTO 3: TESTE PARA PROTEÍNAS}

As proteínas são grandes moléculas formadas pela união de várias moléculas menores, os aminoácidos. Sua função principal é estrutural, mas também podem servir como fonte de energia, catalisadores biológicos (enzimas) e mecanismos de defesa do organismo (anticorpos). Nesse experimento vamos identificar quem apresenta proteínas em sua composição, o açúcar de cozinha ou o leite em pó.

$$
\begin{aligned}
& \text { - Dissolva na placa } 5 \text { gotas de sulfato de cobre em água. } \\
& \text { - Adicione } 5 \text { gotas de hidróxido de sódio. } \\
& \text { - Adicione uma colher de leite em pó e misture a solução. } \\
& \text { - Com que cor ficou a solução? } \\
& \begin{array}{l|l}
\text { Etapa II } & \text { - Repita o processo utilizando açúcar de cozinha ao invés do leite. } \\
\text { - Com que cor ficou a solução? }
\end{array}
\end{aligned}
$$

Quando em meio de pH básico (como uma solução de hidróxido de sódio), os átomos de cobre do sulfato de cobre interagem com os átomos de nitrogênio dos aminoácidos, formando um complexo de coloração roxa. Sendo assim, como podemos explicar a diferença entre a coloração das etapas I e II?

\section{EXPERIMENTO 4: TESTE PARA ÁCIDOS NUCLÉICOS}

Os ácidos nucléicos são compostos orgânicos formados por unidades menores, os nucleotídeos. Eles são responsáveis pela hereditariedade e pela expressão das informações genéticas, destacando o DNA (ácido desoxirribonucléico) e o RNA (ácido ribonucléico). Neste experimento usaremos uma metodologia caseira para extração de DNA de alimentos utilizados no cotidiano.

\footnotetext{
- Em um béquer, coloque $300 \mathrm{ml}$ de água.

- Adicione duas colheres de sopa de detergente.

Etapa I - Adicione uma colher de chá de sal e misture lentamente.

- Passe a solução para o saco plástico.

- Adicione 3 morangos em pedaços e macere o conteúdo.
} 

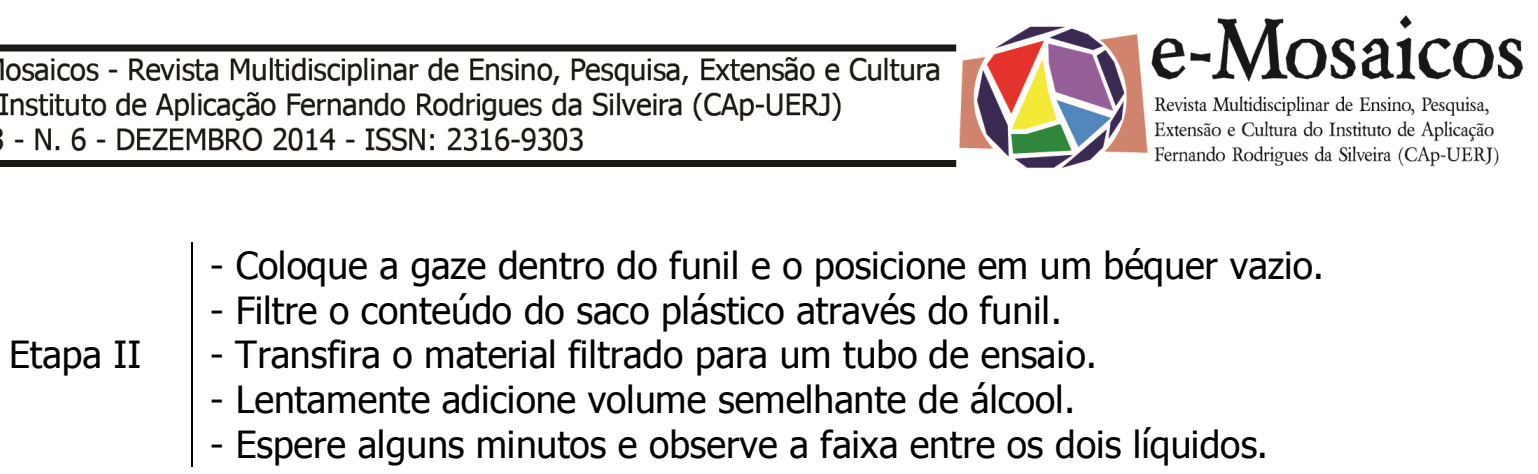

A primeira etapa do experimento tem o objetivo de quebrar as membranas existentes nas células. Considerando seu conhecimento sobre células eucarióticas, explique porque esse procedimento é essencial para o sucesso do experimento.

Relembrando o que você já aprendeu, faça uma correlação entre a estrutura do DNA e a aparência semelhante a "fios de cabelo" do material extraído no experimento. 